\title{
The Digital Divide in Eswatini: Viewpoints of the Millennials
}

\author{
Tibo M. Kiefer, Carin Venter \\ School of Computer Science and Information Systems \\ Faculty of Natural and Agricultural Sciences \\ North-West University, South Africa
}

\begin{abstract}
Developing countries continue to be vulnerable to, and adversely affected by, the digital divide $(D D)$. The study explored the perspectives of affected individuals in a poor, developing African country, i.e., Eswatini, regarding factors that contribute towards a $D D$. The researchers identify in this study the factors that cause the DD, and efforts that can, according to the participants, overcome the technological epidemic in their country. The interpretive research method that was applied was complemented with an approach from the systems thinking field - the researchers structured the study by means of soft systems methodology (SSM). It enabled a better understanding of the social context, and the problem situation, from the viewpoint of those that are mostly affected by it. SSM was useful to systematically guide the enquiry of this problematical techno-social context. The researchers interviewed students at the main campus of a leading University in Eswatini. Students were chosen as the participants since searches about the perspectives of younger generations regarding the affects of and solutions to, the DD yielded few results, indicating a gap in the body of knowledge. However, this generation (i.e., the millennials) are known as the digital generationthey want to partake in the digital and information era. The outcome of the study is a number of factors that the students of Eswatini perceive to be oppressing them by causing the DD, and ways to overcome itthey are frustrated and accordingly vocal regarding the negative effects and the causes of the $D D$, and they want the situation to change.
\end{abstract}

\section{Introduction}

The digital divide (DD) is present globally, in both developed and developing nations. It refers to unequal divisions of technology - where a DD is present, it implies information and communication technology (ICT) divides people through the effective use (or not) and availability (versus the non-availability) of ICT, within and among different nations [1]. It continues to be an oppressing structure that consists of, and results in, divisions between the rich and poor-it intensifies the ever-increasing socio-economic gaps. It is caused by access to, and use of ICT, but as a result of the huge disadvantages that it brings about, it is also referred to as a "knowledge gap" [17].

Access to, and effective use of, ICT correlates with higher levels of education, which is fundamental to achieve global socio-economic evenness [9]. ICT can consequently potentially bridge the $\mathrm{DD}$, and investing in education through ICT will benefit all nations to overcome the DD and its effects [6]. However, the DD is characterized by a perceived inability to invest aptly in ICT, which has the knock-on effect of impacting negatively on levels of education in these countries; e.g., limited access to technology at the school level makes it difficult for students entering University; so, they already start with a disadvantage in this regard. Regardless of their country of origin, this generation (i.e., the millennials) grow up in a digital world - they are (and want to be) connected by means of ICT and information.

Technological advancements underpins the global economy to a large extent and, since the developing countries often lack the infrastructure, resources and skills to bridge the DD, they thus tend to struggle to participate effectively in the information era, and are therefore negatively affected [3]. As an example, less than $10 \%$ of people in developing countries has access to or uses the internet [18].

In this study, the researchers explored viewpoints of the younger generation (i.e., the students) in the Kingdom of Eswatini (formerly Swaziland) regarding the DD; they identified the factors that the students consider to be contributing to the DD in Eswatini, the effects on them, and the efforts that they think can be made to bridge it. The young generation are, and will continue to be, deprived by the DD in their country; however, because of the current political regime, they feel that they do not have a voice - they do not they have a platform where they can raise their concerns and be heard; they are the next generation of leaders and their voices should be heard so as to determine how the DD affect them, and how it can, according to them, be improved. 
The paper is organized as follows: Section 2 gives a brief overview of the research design. In Section 3 the key concepts of the study are discussed. Section 4 gives an overview of the empirical study. A discussion of the results is given in Section 5. Lastly, Section 6 provides an overview of the conclusions.

\section{Research design}

The research is structured according to a research approach that proposes that an area of (social) concern (A) is best investigated when an applied methodology (M) that is rooted in a philosophical framework $(F)$ is used to identify the required improvement [10]. It is referred to as the FMA framework (See Figure 1).

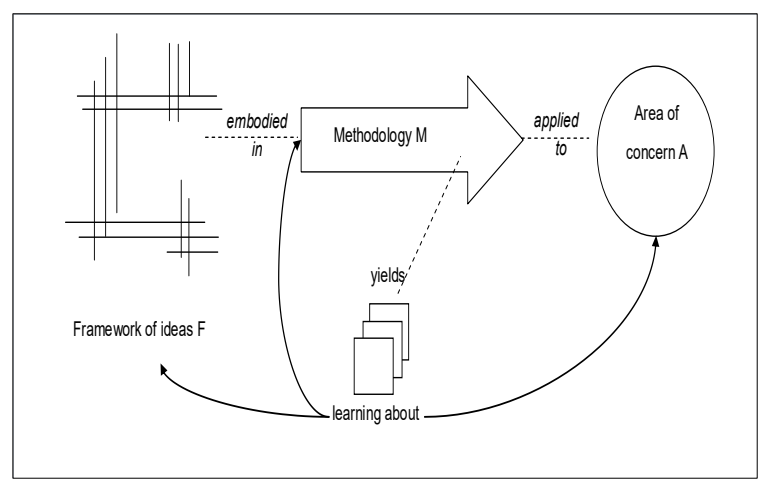

Figure 1. FMA framework

The researchers used the FMA framework as the basis whereby to structure the interpretive study (see Figure 1). They explored the perspectives of students in a developing country (Eswatini), where the citizens are negatively affected by a DD, are as follows:

- The area of concern (A) expresses the purpose and motivation of a study; it entails a real-world situation that should be investigated, so as to improve the social context of those affected by it, such as the individuals affected by the DD. The study focused on students, as the next generation that want to partake in and benefit from economic activities.

- The methodology (M) that was applied in the study was SSM, i.e., a reflective methodology that is based, in terms of the underlying philosophical foundation $(\mathrm{F})$, on the principles systems thinking. Accordingly, SSM was used to structure the research - it was used to develop the open-ended interview questions; and it was applied to make sense of and interpret collected data, as well as present the results.

\section{The key concepts of the study}

The key concepts are a DD, SSM and the principles of systems thinking. They are discussed next, so as to create a shared understanding thereof.

\subsection{The digital divide}

A DD is essentially a separation in that it isolates individuals (and nations); it divides along the lines of the ones that cannot obtain access to ICT, and the ones that can obtain access [15]. The DD implies that there are imbalances in terms of access to technology, and therefore the benefits that the technological advances bring about $[1 ; 3]$. It entails inconsistency in terms of private and public access to ICT infrastructure as well as access to (local and global) information [7].

The DD result in individuals having limited access (or even no access at all) to ICT and/or information resources, and as such it deepens and increases widespread inequality [5]. A DD is an imbalance between online versus non-online communities - it divides the so-called 'haves' and the 'have not's', the rich and the poor; the DD divides the developed and developing nations; and in some cases, even causes disparities between men and women [7]. The central truth is that the DD causes an oppressing structure that impedes suitable growth, development and progression.

The DD is caused by a number of different factors. It also has numerous negative effects. These are, for example, economical, social and cultural causes; and high cost vs low quality of existing ICT infrastructure, and overall technology acceptance may result in a DD. These factors impact on each other and should not be viewed in isolation.

It has been proved that the appropriate adoption of technology drives economic growth; a weak economy will restrict investment in suitable (and much needed) technological infrastructure $[4 ; 5]$. Moreover, cultural differences may affect perceptions regarding the use and usability of technology, which may influence the adoption and use thereof, which then, in turn, will also negatively affect economic growth [4]. Research have also indicated that the DD results, overall, in lower levels of education; however, ironically, higher levels of education is often cited as one of the key factors to overcome the DD [6;9].

A DD is a divide that is egalitarian for individuals that choose to use digital resources (or not) and are hence able to participate and engage publicly in terms of mobilization and technology. DDs are present in developed countries; though, it is developing nations that are mostly affected by it. ICT continues to grow and advance rapidly, but the DD remains, and the DD is forever widening in developing countries [16].

\subsection{Systems thinking}

The word 'system' was originally used to describe physical entities and the representation of components that make up a unit, which could effectively be broken down into its identifiable individual components. This mechanistic viewpoint enabled accurate definition of 
t system, that can be assembled to achieve its defined objectives, and deconstructed into its components to systematically analyze it, in order to holistically solve problems that arise from using it [12]. This comprised the traditional 'hard' systems viewpoint.

However, from the 1980s onwards, the concept of a system was extended to also apply to problematical social contexts. Moreover, the principles of systems, and system thinking, was applied to explore situations that involve human participants, i.e., contexts that cannot be easily broken down into recognizable parts, yet, were viewed and investigated as a holistic system. In this 'soft' systems view, a system entails the coherent whole entities that are explored from the perspectives of the different ways whereby (diverse) individuals conceptually organize their thoughts about their views of (their) world, rather than a description of something that is uniform and/or tangible in the world [12].

From this perspective a social context (as a system) can be explored conceptually to understand the status quo - the concept of a system is applied as an abstract tool to explore complex social situations and contexts, and SSM operationalizes this view of soft systems thinking [2;11].

\subsection{Soft systems methodology}

Peter Checkland developed SSM to better explore and understand the ill-structured, messy and complex social contexts that oppressed individuals have to deal with; it is therefore useful to explore the perspectives of participants regarding the impact of a situation on them, and also how they think it could be resolved [2] (see Figure 2).

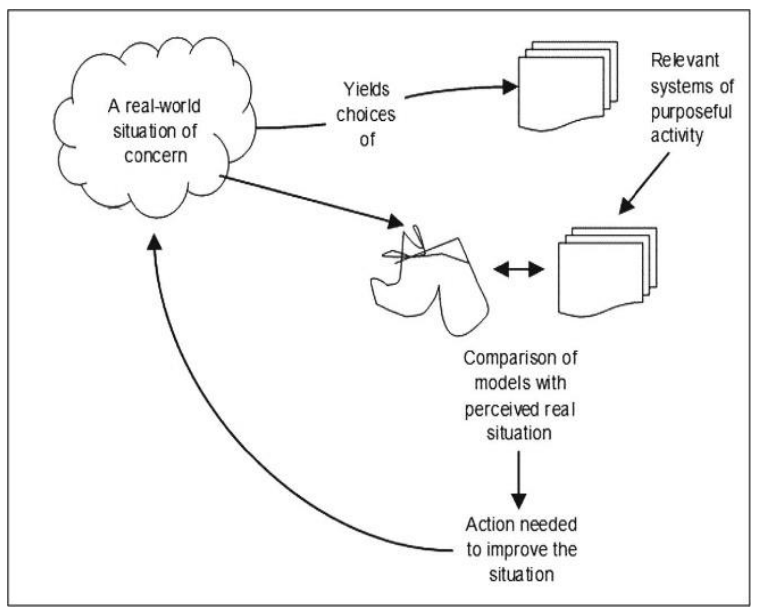

Figure 2. Purposeful activity process of SSM

SSM facilitates understanding of action-to-improve, through understanding of the world views of affected individuals, and hence enable problem solvers to act. So, when using SSM, problem solvers (or researchers) identify the purposeful activities that could potentially improve the identified problematical social situation.

In the context of SSM, purposeful activity requires a problem solver (researcher) to take part in a cyclical process where s/he learns about a situation, construct models of actions for improvement, compare it to realworld models of the status-quo, and define purposeful actions for improvement. It is illustrated next.

Therefore, when applying SSM to explore a social issue, a researcher must identify areas of improvement and actions for improvement from the perspectives of those that are affected most by it, i.e., "through whose eyes 'improvement' is to be judged", in addition to considering factors such as relevant cultural, political and/or historical influences [2] (see Figure 3).

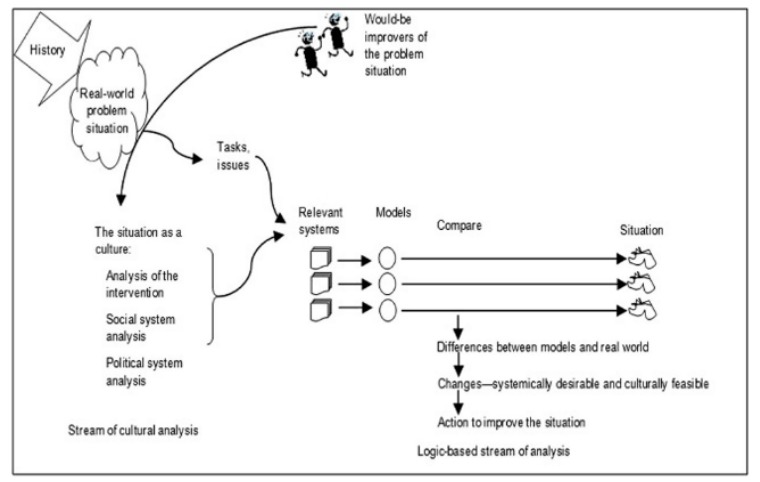

Figure 3. The SSM process, adapted from [2]

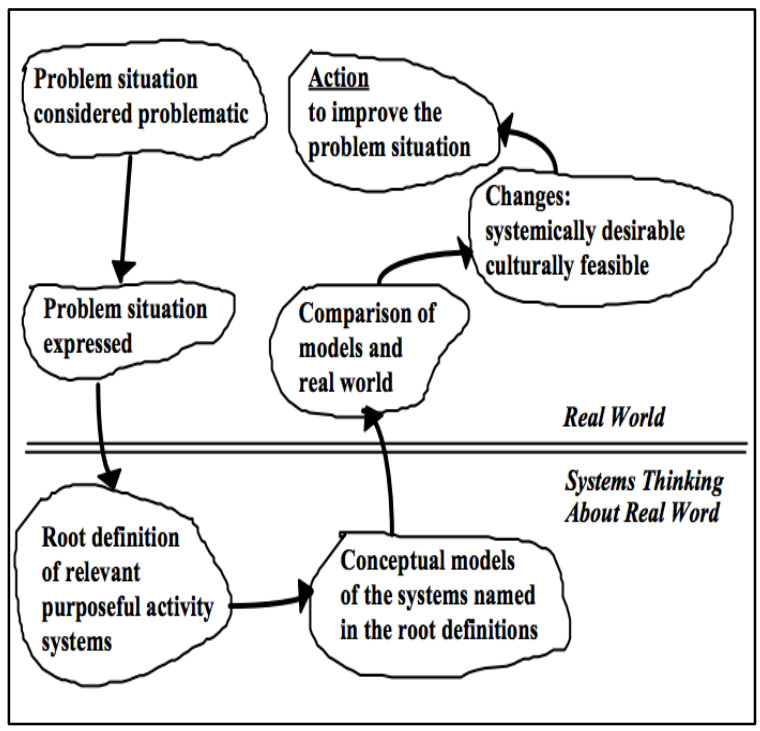

Figure 4: The SSM steps

On a practical level, SSM has been applied in ICT related research, specifically to explore social impacts of ICT systems. It is quite useful as it facilitates proper understanding of the diverse perspectives of affected individuals. It is practical in that it provides a step-bystep guide to determine an as-is (real) versus the to-be (ideal) context, as perceived by the affected. 
The SSM steps include the following: identify and express the problem context and situation; derive the relevant root definitions; develop conceptual models of the actual versus the to-be situation; and identify required changes (i.e., the transformation). The Figure 4 show the flow and sequence of the steps.

The outcome of the SSM steps can be presented in the form of rich pictures, then also serve as conceptual models of the as-is versus to-be context. Rich pictures are free-hand illustrations of a situation, as perceived, and the desirable changes, as per the understandings, and outcomes as was discussed with and among the involved and affected stakeholders.

In SSM the development of root definitions entails a process to define purposeful transformation actions. Root definitions outline steps to take, so as to achieve the ideal state, and state the what, why and how of the change. Root definitions are defined by considering the involved and affected customers, actors, changes/ transformations, world views, owners, as well as the environmental (CATWOE) aspects of a problematical social context, as follows: consider the customers, i.e., those that want a change; the transformation, i.e., the change that is required; the owners, i.e., those that have the power to mandate the implementation of the transformation; the actors, i.e., those that must follow instructions and implement a transformation; enablers and/or constraints of the environment to be taken into account for success; and all the relevant, yet diverse, world views of the involved and affected stakeholders, i.e., referring to the outlooks that affect, for example, how/why people act in a specific way [2].

\section{The empirical study}

The primary objective of the study was to explore the perspectives of students in Eswatini regarding the DD; the researchers identified factors that the students perceive as contributing to the DD in their country, in addition to what could be done to improve upon it, and by whom. The use of SSM in this study, to explore their viewpoints regarding the DD, is discussed next. This section also explains the selection of participants, the data collection, and data analysis approach. Lastly, the study's results are discussed.

\subsection{The use of SSM in the study}

In this study's context the CATWOE dimensions were defined as follows: customers are the students that want to overcome the negative effects of the DD; actors are those that must implement the actions for transformation (i.e., as is required to bridge the DD, according to the students), but do not necessarily have the power to order or enforce the specific actions to be implemented; the transformation required entails the steps that should be taken, according to the students, to overcome the DD; the owners are those that have the power to halt change, according to the students; pertinent environmental aspects refer to the relevant issues that the students perceive to cause the DD, and should be overcome; and, lastly, relevant world views of the students regarding the DD are to be identified.

Taking the above into account, interview questions were derived, e.g., to cognize a student's environment and/or constraints in terms of access to typical ICT infrastructure and the internet, which impacts on their internet use; e.g., questions that were formulated are: "How and where do you have access to the internet?"; "What are challenges that deal with when using the internet?"; "How are you affected by the fact that English is the dominant language on the internet?"; "Which device do you prefer when using the internet? Why?" and "Tell me about the computer facilities you have at home?".

Furthermore, to understand political, economical and historical matters, participants were asked about the impact that the cost and speed of the internet have on them; about the computer facilities they had/have at home; and the facilities they had in school (primary and high school), e.g., "Tell me about the computer facilities you had when you were in primary and high school?"; and "What type of computer and/or internet training do/did you receive?". Also, participants were questioned regarding their world views in terms of, e.g., opinions about required transformations, e.g., in terms of the infrastructure, service providers, access to training, etc.

\subsection{Participants}

Interpretive research requires a sufficient amount of eligible participants to ensure valid results, i.e., data saturation must occur. So, when data are analyzed and no new codes or themes emerge, data saturation have been obtained [13;14].

In this study, a representative sample of the student body of actively enrolled students at the main campus (situated in the capital Mbabane) of the University of Eswatini participated. The participants were randomly selected from all the departments that are represented at the University. Consent to conduct this study was obtained from the main campus of the University in Eswatini. Participation were voluntary-participants were assured that their answers would be anonymous and confidential.

\subsection{Data collection}

Data were collected through open-ended and semi-structured face-to-face interviews. Interviews were mainly conducted in English, but the participants were allowed to respond in their native language (siSwati). All responses were translated by the interviewer (the interviewer's first language is siSwati; and his second language is English).

All the interviews were recorded and transcribed. Collected data were coded and categorized after each 
interview and then added to the data repository. The interview process continued until data saturation was reached and no new codes emerged - a total of 20 interviews were conducted. The interviews provided rich, qualitative data.

\subsection{Analysis of collected data}

It is helpful to apply a guiding framework when carrying out social analyses, as per the aim of the study, i.e., understanding perceptions of individuals affected by the DD, so as to suggest intervention(s) to improve it. Accordingly, the researchers applied the CATWOE dimensions as overarching themes so as to make sense of gathered data, and present the outcome.

First, data were coded, and categories were formed by grouping codes, based on their relationships. The categories were then placed in a corresponding theme, as per the CATWOE dimension where it applies.

For example, participants could indicate that they had/have access to 'no ICT, 'limited ICT or 'adequate ICT, and the access could be applicable to the current place of 'residence', an/or (historically) in the former 'primary school' or 'high school', and/or currently 'at University'. Moreover, the researchers distinguished between types of ICT that they had access to, e.g., they could have access to the 'internet', an owned or University provided or internet-café 'desktop' and/or 'laptop computer' and/or a 'smartphone'. They also differentiated between typical purposes and what they used ICT for.

Secondly, when data saturation was reached and all the codes were derived and also categorized, they were allocated to identified themes, i.e., as belonging to one of the CATWOE dimensions. For instance, as the previously availability of ICT infrastructure was indicated by the majority as a draw back in terms of partaking in the global economy, it was positioned as something that must change, and so it was indicated as an action for transformation. The complete set of results is discussed next.

\subsection{Results}

The students, as the customers in the study, had similar world views regarding the DD and ICT usage. All the participants (20) could aptly define a DD prior to the onset of the interview. So, they were all aware of it and its effects. They agreed that it was something that oppressed them and should be eliminated. Even though 1 of the participants was prejudiced towards the use of ICT, all the rest (19 of the 20 participants) accepted and embraced the use of ICT and were in favor of it being applied to their benefit.

All the participants (20) indicated that they use the internet for entertainment and academic work. Most participants (19) indicated that they used computers for academic work, and many (16) also used it for fun, e.g., to watch Netflix, listen to music or play games.
The students had limited access to ICT (computers and the internet) at University - they were given 3GB monthly. However, the majority of the participants indicated that they had either no access to ICT at home (11), or that they had limited access, e.g., a computer but not internet access (7). Only 2 of the participants indicated that they had full access to ICT in their own homes. 11 participants indicated a device preference for smartphones, while 6 preferred to use a laptop and only 4 preferred to using a desktop computer - this may be due to familiarity, as all of the participants had their own mobile phones.

With reference to schools (and thus a historical perspective for these participants), many of them (13) had complete access to full ICT in high school, but not in primary school. Still, all participants indicated that they struggled to access the internet, due to different reasons cited, e.g., lack of skills, lack of access, poor infrastructure, slow connections, technical issues, lack of workspaces, etc.

It was interesting to note that only 5 participants found the fact that the internet is mostly in English a barrier to using it; 15 were comfortable with it as-is.

Infrastructure issues and poor service provision, as well as high costs were mentioned as issues - all (20) regarded the service quality as too low; and 14 said it was too expensive. The participants mentioned that a monopoly service provider was providing all services, and it may be a reason for poor quality and high costs. The results are visually presented in the concise rich picture in Figure 5.

In formulating root definitions to clarify a research context and describe how to transform it for the better, statements must be formulated to indicate who should do what, as well as how, in addition to why, i.e., state the purpose(s) for change, transformation action(s), and reason(s) for needing the change. Furthermore, it is required to take note who should take accountability to implement the changes. Therefore, in considering the analyzed data, the following root definitions were derived:

Firstly, in terms of service delivery, it became clear that participants wanted the government to eradicate monopoly service provision and believed it would lead to better services. Secondly, in terms of the ICT infrastructure, the government should build better and more useful infrastructure. Thirdly, improvement in the relevant skills could be attained if the educational institutions, such as the Universities and schools, in collaboration with the government, provide suitable courses. Fourthly, the students (and citizens) should accept technology, and in doing so it may be required to change some historical, cultural and/or political viewpoints that are hindering technology adoption. 


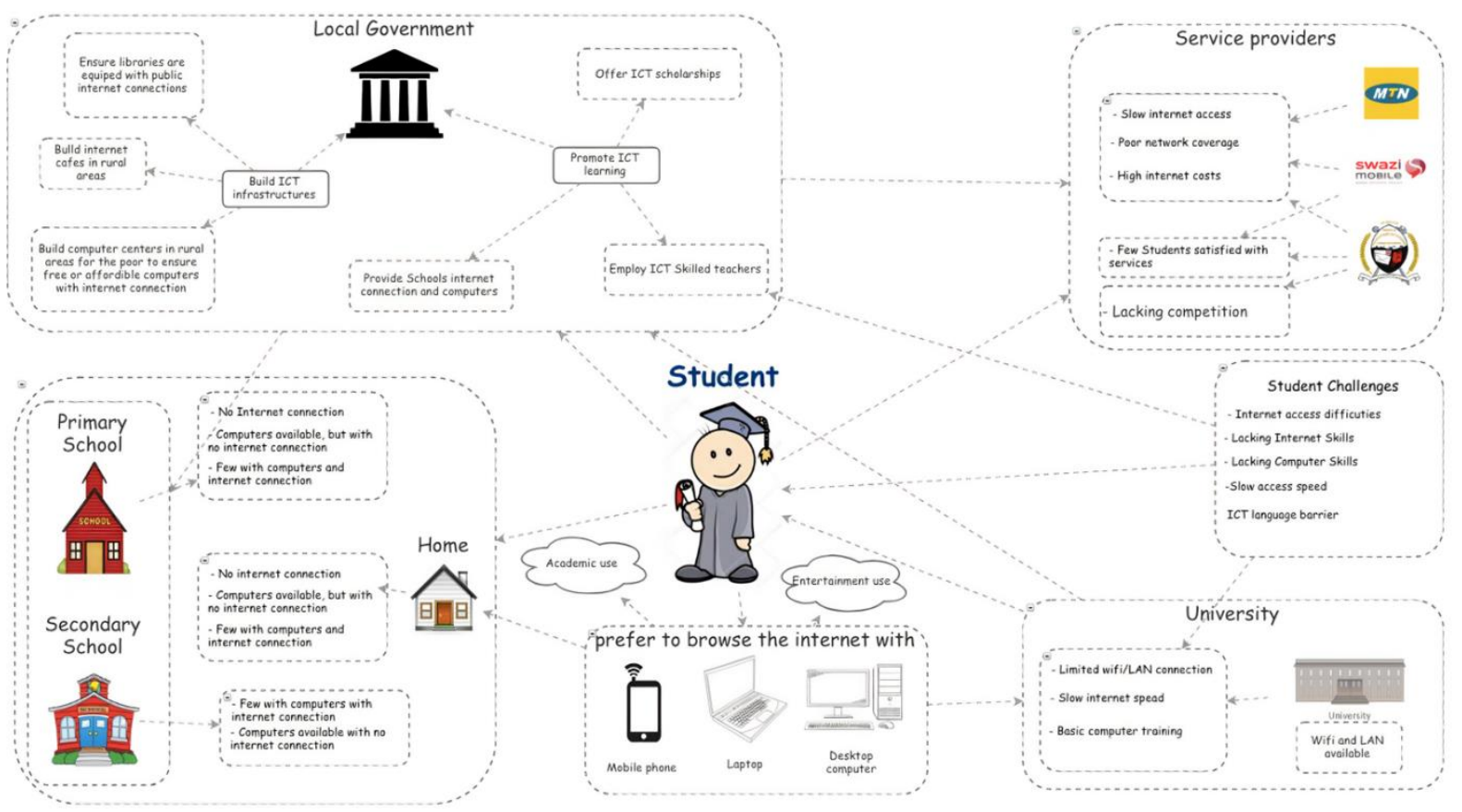

Figure 5: Rich picture of student perspectives re DD

\section{Discussion}

The first theme was not derived from participant's responses; rather, it entailed the participants, since the (millennial) students were regarded as the customers. Codes were therefore note generated for this theme.

The transformation that the participants indicated as mandatory to improve the DD in Eswatini was related to a number of factors. Access to ICT from an early age was mentioned as important. Those that did not have access to ICT at all (i.e., 7 out of 20) felt that they were disadvantaged and struggled at University to learn the ICT skills required to study effectively. They believed that ICT should be applied effectively and that it is imperative for proper education. This also aligns with the issues identified in the literature regarding causes of a DD, and the popular views that this generation want to be connected to information.

Only 1 participant indicated that $s /$ he finds ICT, in general, not of great use and that ICT should particularly not be made available to children; s/he believes that "...young children...misuse it and play games..." S/he also said further that "I was told by my parents that technology is not good." Yet, the majority (19) believe that the ICT networks and access should be expanded in the country as a whole, e.g., a participant said that "The ICT ministry should build computer centers for people in rural areas, in order for them to access the internet and computers... The government should ensure that every library in the country...have computers and the internet." The participants agreed that ICT is more accessible in the urban areas, but said that accessibility is still not sufficient, and quality and costs are mentioned as major drawbacks.

So, even though all the participants used ICT, they found the environment was still unfriendly towards ICT usage: 20 participants (all of them) struggled with internet access and found it frustrating to use; 5 of the participants indicated that they lacked skills to use the internet effectively-they were not granted sufficient opportunities to acquire the necessary skills. Again, it reiterated that the millennials want to be able to access information fast.

The participants also complained about the inferior state of computers in laboratories and student centers on campus. Most of the participants prefer to use their mobile devices over desktop and laptop computers-perhaps because they are more accessible. However, the smaller screens were also said to hinder effective use for educational purposes.

The owners and/or actors as per the governance and service provision model of ICT in Eswatini were identified as government agencies and also businesses controlled by the government. The participants did not distinguish between the roles of owners and actors, as per the definition provided by [2]. They argued that those that are in control of underlying infrastructure and investments, were the same ones that should act to improve upon it-for example, they regarded the monopoly service providers as a main cause of poor service delivery and low-quality infrastructure, and also inadequate service (according to all participants) and outrageously high (unaffordable) costs (according 
to 14 of the participants). When comparing the service providers, the participants agreed that the (somewhat) better services of one came a very high price; while the other was a little more affordable, yet too slow to be effective during peak hours. Regardless, both of the providers had to use the sole internet provider's ICT infrastructure.

As a result, participants perceived the government and government policies that allow monopoly service providers to continue to provide poor infrastructure and services at high costs, as a barrier to effective service delivery, infrastructure and costing models, and as such a cause of the DD. They argued that, to improve infrastructure, service and cost, monopolies should be eradicated, and that the investment models and policies must change-it will result in better service delivery, lower costs and also improved infrastructure.

The participants also wanted more infrastructure in rural areas, more access to relevant ICT training, and access to ICT equipment at a younger age, so as to better prepare them for University, and the global economy at large. The students are of the opinion that, as the generation that must work towards becoming economically active, they are mostly affected by the DD in school, at home, and at University, as per the service delivery of (monopoly) service providers and the general lack of government support, and they want it to change.

\section{Conclusions}

The researchers explored the viewpoints of the younger generation, i.e., the millennials, which could potentially also be the next generation of leaders in the country, i.e., they interviewed the University students in Eswatini regarding the DD.

SSM was used to structure the study, guided the interviews, and eased the analysis of rich qualitative data. With the use of SSM, a visual presentation of the viewpoints of the students clearly demonstrated their burning issues. For example, the rich picture provided a clear picture of the perspectives of the students, and the formulation of the root definitions brought about clarity of the DD context and described how it could be transformed for improvement.

A number of factors that the students regarded as causing the DD in their country were identified. These factors aligned with the literature as to general causes of a DD. It was also clear that they are frustrated and felt oppressed by the DD. The students are a part of the digital (millennial) generation, and they want to partake in the digital and information era.

They were very vocal in that they openly blamed their government bodies, the investment policies and monopoly service providers for a persistent, widening DD. They were convinced about the causes of the DD and what could be done to improve it. The majority of the students indicated that they wanted to become part of the global information era; however, they continue to feel frustrated and oppressed by the lack of good ICT infrastructure and the poor service delivery. The study provided rich insights as to the factors that the students regarded as contributing to the DD in their country. It gave the insight that it is a huge problem for them. Furthermore, they also indicated what they perceive to be required to transform in this regard.

\section{References}

[1] Ali, A.H. (2011). The power of social media in developing nations: New tools for closing the global digital divide and beyond. Harvard Human Rights, 24(1):186-219.

[2] Checkland, P. and Scholes, J. (2000). Soft systems methodology in action: a 30-year retrospective. Chichester: Wiley.

[3] Chen, W. and Wellman, B. (2004). The global digital divide - within and between countries. IT and society, 1(7):39-45

[4] Erumban, A.A. and De Jong, S.B. (2006). Cross-country differences in ICT adoption: A consequence of Culture? Journal of World Business, 41(4):302-314.

[5] Kularski, C. and Moller, S. (2012). The digital divide as a continuation of traditional systems of inequality. Sociology, 5151(15):1-23.

[6] Mariscal, J. (2005). Digital divide in a developing country. Telecommunications policy, 29(5):409-428.

[7] Norris, P. (2001). Digital divide: Civic engagement, information poverty, and the Internet worldwide. $1^{\text {st }}$ ed. Cambridge: Cambridge University Press.

[8] Oates, B.J. (2006). 'Researching Information Systems and Computing', SAGE.

[9] Schweikart, L. (2002). Race, Culture and the "Digital Divide". Ideas on Liberty, 44-47.

[10] Checkland, P., Holwell, S. (1998). Information, Systems, and Information Systems: Making Sense of the Field. Wiley, Hoboken.

[11] Vickers, G. (1984). Human systems are different. Business Horizons. 27(5):83-84.

[12] Checkland, P. (2021). Four conditions for serious systems thinking and action. Systems Research and Behavioral Sciences. 29(5):465-469.

[13] Seidman, I. (2013). Interviewing as qualitative research: A guide for researchers in education and the social sciences. $4^{\text {th }}$ ed. New York: Teachers college press.

[14] Seale, C. (1999). Quality in qualitative research. Qualitative inquiry, 5(4):465-478.

[15] Henry, L. (2004). The digital divide, economic growth and potential poverty reduction: The case of the English speaking Caribbean. Journal of Eastern Caribbean studies, 29(1):1-22. 
[16] Gonçalves, G., Oliveira, T. and Cruz-Jesus, F. (2018). Understanding individual-level digital divide: Evidence of an African country. Computers in Human Behavior.

[17] De Beer, C. (2007). Africa in the globalising world: digital divide or human divide? Communication Research, 33(2):196-207.

[18] Guillén, M.F. and Suárez, S.L. (2005). Explaining the global digital divide: Economic, political and sociological drivers of cross-national Internet use. Social Forces, 84(2):681-708.

[19] Loveland, E. (2017). Instant Generation, Journal of College Admission, 234:34-38. 